www4.fsanet.com.br/revista

Rev. FSA, Teresina, v. 18, n. 03, art. 12, p. 260-278, mar. 2021

ISSN Impresso: 1806-6356 ISSN Eletrônico: 2317-2983 http://dx.doi.org/10.12819/2021.18.03.12

\title{
Revisão Sistemática das Produções do Laboratório de Pesquisa em Psicologia Ambiental
}

Systematic Review of the Productions of the Research Laboratory in Environmental Psychology

Fábio Pinheiro Pacheco

Doutorado em Psicologia pela Universidade Federal do Ceará Mestre em Psicologia pela Universidade Federal do Ceará E-mail: pfabiopinheiro@gmail.com

Luiza Eridan Elmiro Martins de Sousa

Doutorado em Psicologia da Universidade Federal do Ceará, Fortaleza Mestra em Políticas Públicas e Sociedade pela Universidade Estadual do Ceará E-mail: luizaeridan@gmail.com

\section{Zulmira Áurea da Cruz Bonfim}

Doutorado Psicologia Social pela Pontifícia Universidade Católica de São Paulo Mestra em Psicologia pela Universidade de Brasília E-mail: zulaurea@gmail.com.

Endereço: Fábio Pinheiro Pacheco

Av. da Universidade, 2762, Benfica - Área 2 do Centro de Humanidades - Bloco Didático Prof. Ícaro de Sousa Moreira, CEP: 60.020-180 - Fortaleza, Ceará. Brasil. Endereço: Luiza Eridan Elmiro Martins de Sousa Av. da Universidade, 2762, Benfica - Área 2 do Centro de Humanidades - Bloco Didático Prof. Ícaro de Sousa Moreira, CEP: 60.020-180 - Fortaleza, Ceará. Brasil. Endereço: Zulmira Áurea da Cruz Bonfim

Av. da Universidade, 2762, Benfica - Área 2 do Centro de Humanidades - Bloco Didático Prof. Ícaro de Sousa Moreira, CEP: 60.020-180 - Fortaleza, Ceará. Brasil.
Editor-Chefe: Dr. Tonny Kerley de Alencar Rodrigues

Artigo recebido em 09/02/2021. Última versão recebida em 24/02/2021. Aprovado em 25/02/2021.

Avaliado pelo sistema Triple Review: a) Desk Review pelo Editor-Chefe; e b) Double Blind Review (avaliação cega por dois avaliadores da área).

Revisão: Gramatical, Normativa e de Formatação 


\title{
RESUMO
}

Este artigo apresenta uma revisão sistemática das produções do Laboratório de Pesquisa em Psicologia Ambiental no Programa de Pós-Graduação em Psicologia da Universidade Federal do Ceará. Discute as perspectivas teóricas, as temáticas estudadas e os métodos adotados dos estudos realizados entre 2003 e 2020. A Psicologia Ambiental e a Psicologia Social são as principais bases teóricas. A metodologia é de maioria qualitativa, com abordagem multimétodos, utilizando-se o Instrumento Gerador de Mapas Afetivos e a Entrevista como ferramentas de coleta de dados. A Análise de Conteúdo é a principal abordagem de trabalho das informações. Conclui-se que as pesquisas abordam temáticas de contextos diversos, produzindo conhecimento a partir das demandas emergentes da sociedade, demarcando uma produção interdisciplinar e ética, politicamente engajada acerca da relação pessoa-ambiente.

Palavras-chave: Psicologia Ambiental. Revisão sistemática. Pós-graduação. Locus.

\begin{abstract}
This article presents a systematic review of the productions of the Research Laboratory in Environmental Psychology in the Graduate Program in Psychology at the Federal University of Ceará. It discusses the theoretical perspectives, the themes studied and the methods adopted in the studies realized between 2003 and 2020. Environmental Psychology and Social Psychology are the main theoretical foundations. The methodology has a qualitative majority, with a multi-method approach, using the Affective Maps Generating Questionnaire and the Interview as data collection tools. Content Analysis is the main approach to analysing information. It is concluded that the research was realized in different contexts, producing knowledge from the emerging demands of society, demarcating an interdisciplinary and an ethical-political position engaged in production about the person-environment relationship.
\end{abstract}

Keywords: Environmental Psychology. Systematic review. Postgraduate. Locus. 


\section{INTRODUÇÃO}

O Programa de Pós-Graduação em Psicologia da Universidade Federal do Ceará (PPGP-UFC) surgiu em 2003, 30 anos após o início do curso de graduação, com sua primeira turma de doutorado em 2015 (BARROS et al, 2019). O programa conta com três linhas de pesquisa: 1) Teorias e Práticas da Psicanálise, que realiza investigações teóricas e clínicas sobre a constituição do sujeito, modos de organização psíquica e processos sintomáticos patológicos; 2) Sujeito e Cultura na Sociedade Contemporânea, faz um debate crítico e ético sobre a cultura tardo-moderna, abordando as subjetividades contemporâneas afetadas pelo consumo, as mídias e as novas tecnologias, as experiências de compreensão do tempo e as formas de controle e regulação social; e 3) Processos Psicossociais e Vulnerabilidades Sociais, que, a partir da psicologia social, investiga as interações sociais constitutivas do humano, refletindo temáticas como o trabalho, comportamentos e culturas organizacionais, relações dos sujeitos com a comunidade e o ambiente, abrangendo contextos de desigualdades sociais e seus efeitos psicossociais sobre o bem-estar individual e coletivo (LIMA et al, 2018; BARROS; ANTUNES; MELLO, 2020).

Segundo Barros et al. (2019), a especificidade que integra as linhas e articula o PPGPUFC à graduação é a vinculação das pesquisas à atuação extensionista, “[...] cujo aprofundamento teórico e científico, por sua vez, respalda a compreensão e construção de conhecimentos acerca do processo de subjetivação na sociedade contemporânea" (p. 149). Nesse sentido, há uma orientação das pesquisas para a “[...] problematização de questões envolvendo políticas de vulnerabilidade social e seus diversos efeitos, a partir de diferentes prismas teórico-metodológicos" (BARROS et al., 2019, p. 154).

Ademais, o programa mantém vínculo estreito com a graduação a partir da relação entre as linhas de pesquisa e os núcleos e laboratórios do Departamento de Psicologia (Lima et al, 2018). A linha de Teorias e Práticas da Psicanálise relaciona-se com o Núcleo de Estudos sobre Drogas (NUCED) e ao Programa Clínica, Estética e Política do Cuidado. À linha Sujeito e Cultura na Sociedade Contemporânea, vinculam-se o Laboratório de Psicologia em Subjetividade e Sociedade (LAPSUS), o Grupo Interdisciplinar de Estudos, Pesquisas e Intervenções em Psicologia Social Crítica (PARALAXE) e o Grupo de Pesquisa Nexos/NE. Por fim, a linha Processos Psicossociais e Vulnerabilidades Sociais relaciona-se com o Núcleo Cearense de Estudos e Pesquisas sobre a Criança (NUCEPEC), o Núcleo de Psicologia Comunitária (NUCOM), o Núcleo de Psicologia do Trabalho (NUTRA), o Laboratório de Psicologia Ambiental (LOCUS), o Laboratório Cearense de Psicometria 
(LACEP) e o Grupo de Pesquisas e Intervenções sobre Violência, Exclusão Social e Subjetivação (VIESES) (BARROS; ANTUNES; MELLO, 2020).

Neste trabalho, enfatizamos a relação do PPGP-UFC com o LOCUS, este surgido em 2003, fazendo parte do Departamento de Psicologia da UFC. O laboratório constrói uma perspectiva socioambiental, por meio de uma visão psicossocial e sóciohistórica, para compreender a relação pessoa-ambiente, abrangendo as dimensões física, social, cultural, psicológica e política, direcionando seus estudos e intervenções às demandas emergentes da sociedade. Seus aspectos teórico-metodológicos são interdisciplinares, por considerar a complexidade dos fenômenos estudados e a multiplicidade de fatores envolvidos nas interações pessoa-ambiente (ELALI; PELUSO, 2011), estabelecendo redes de atuação com as áreas da Psicologia, Educação, Geografia, Arquitetura e outras disciplinas.

$\mathrm{Na}$ Psicologia, fundamenta-se principalmente, nos pressupostos teóricos e metodológicos da Psicologia Social latino-americana (LANE, 1989; MARTÍN-BARÓ, 2011) entrelaçada aos da Psicologia Ambiental de base transacionalista (GÁRCIA-MIRA, 1997; BOMFIM, 2010). A afetividade é a categoria norteadora de pesquisa e intervenção (SAWAIA, 2011), justificando-se pela necessidade de desestabilizar as clássicas dicotomias das ciências sociais, tais como subjetivo e objetivo, externo e interno, coletivo e individual, qualitativo e quantitativo, etc., configurando uma dimensão ético-política da ação transformadora, sendo possível, por meio dela, a análise e a superação das desigualdades sociais (BOMFIM, 2010; SAWAIA, 2011). Neste sentido, parte da noção de que existe uma conduta territorial, onde o indivíduo constrói a si mesmo como identidade na relação com o espaço, transformando-o e sendo transformado por ele, atribuindo significado e sentido às suas vivências.

O LOCUS desenvolve ações extensionistas junto à comunidade universitária e à sociedade em geral, com temáticas voltadas para a relação pessoa-ambiente, tendo como propósito a melhoria da qualidade de vida e o exercício da cidadania. Há o desenvolvimento e a aplicação de novas metodologias de investigação e de intervenção, além da construção de processos de ensino sobre a educação ambiental, colaborando no sentido da ampliação e/ou criação de comportamentos pró-ambientais.

Dentre os principais projetos do laboratório, destacam-se o Projeto de Extensão Vida no Campus, que trabalha ações de melhoria da qualidade de vida de alunos, professores e demais funcionários no ambiente universitário; Projeto de Extensão Diagnóstico-ação Psicossocial pela Identificação dos Mapas Afetivos, voltado para o diagnóstico sócioeconômico, infraestrutural, psicossocial e ambiental em comunidades da cidade de 
Fortaleza; Projeto de Extensão Nas Trilhas da Psicologia Ambiental, que visa facilitar o acesso dos usuários dos campi universitários aos processos de apropriação e identificação dos espaços de Fortaleza, utilizando como ferramenta das trilhas urbanas e ecológicas; e o Programa Locus, que desenvolve ações interdisciplinares, tendo suas atividades de pesquisa e extensão, desde 2015, voltadas para etnias indígenas.

Considerando a história do LOCUS, este artigo objetiva analisar as produções acadêmicas do Laboratório de Pesquisa em Psicologia Ambiental, desenvolvidas no Programa de Pós-Graduação em Psicologia da Universidade Federal do Ceará. A partir de uma revisão sistemática, apresentam-se as principais perspectivas teóricas, as temáticas de estudo e os métodos presentes nas dissertações e teses produzidas entre 2003 e 2020.

\section{METODOLOGIA}

Trata-se de uma revisão sistemática, que consiste em um método que amplia buscas sobre determinada temática, possibilitando a construção de um trabalho reflexivo e crítico a partir da sistematização do material a ser analisado (COSTA; ZOLTOWSKI, 2014). A busca foi realizada no site do Repositório Institucional da Universidade Federal do Ceará, tendo como recorte temporal de 01 de janeiro de 2003 a 31 de dezembro de 2020.

Para a seleção dos materiais, foram adotados como critérios de inclusão: I) dissertação e/ou tese orientada pela professora coordenadora do Locus e professora do PPGP-UFC; e II) os textos estarem integralmente disponíveis no Repositório Institucional da UFC. Os critérios de exclusão foram: I) trabalhos repetidos. Foram realizados 25 estudos, tendo sido o primeiro publicado em 2006 e o último em 2020. Estes foram organizados em uma planilha do Excel, conforme autoria, título e ano de defesa, posturas teóricas, temáticas de estudo e procedimentos metodológicos adotados. A avaliação, síntese e interpretação final dos dados se deu com base na estatística descritiva e análise de conteúdo categorial de Bardin (1977).

\section{RESULTADOS E DISCUSSÕES}

A partir da organização e análise dos dados, as informações foram agrupadas em três principais subseções, a saber: I) posturas teóricas, que revela o posicionamento ético-político dos referenciais teóricos utilizados nas pesquisas; II) as temáticas de pesquisa, que descreve os principais objetivos e contextos de estudos; e os procedimentos metodológicos, que 
apresenta os percursos e recursos utilizados pelos pesquisadores para o delineamento e desenvolvimento da pesquisa. A seguir, discute-se cada subseção.

\subsection{As posturas teóricas e o posicionamento ético-político}

A partir da análise dos temas abordados pelo LOCUS, percebe-se o foco nos estudos voltados à compreensão da relação pessoa-ambiente, remetendo-se à Psicologia Ambiental, a partir de um olhar psicossocial, dialógico e dialético, com forte influência da Psicologia Social de base sócio-histórica (LANE, 1989) pautada na concepção da ciência psicológica desenvolvida por Vygotsky (1996) que rompe com as dicotomias do modelo cartesiano. Desse modo, compreende como o indivíduo constrói sua subjetividade em uma relação dialética entre ele e a sociedade e suas instituições, consideradas como ambientes.

Para Moser (1998), o objeto de estudo da Psicologia Ambiental é o indivíduo em seu contexto, ou seja, as inter-relações das pessoas e do ambiente físico e social. Com a visão transacionalista, evidencia-se o entorno como uma dimensão da identidade dos indivíduos nos quais interagem fatores psicossociais, sóciofísicos e histórico-culturais (BOMFIM, 2010). A aproximação entre a Psicologia Social de base sócio-histórica e a Psicologia Ambiental de visão transacionalista busca compreender o encontro do indivíduo com o ambiente. Nessa interface, o lugar se apresenta como parte constitutiva da subjetividade, de maneira que os afetos a ele relacionados estão vinculados às histórias e às identidades dos sujeitos e ao enfrentamento das situações cotidianas nos diversos ambientes.

A afetividade é a categoria primordial das pesquisas realizadas, em especial, os afetos em relação aos lugares. Para Sawaia (2011, p.100), a afetividade, enquanto a integração das emoções e dos sentimentos é entendida como "[...] a tonalidade e a cor emocional que impregna a existência do ser humano". Baseada na filosofia de Espinosa, na sociologia de Agnes Heller e na psicologia de Lev Vygotsky, a autora construiu o conceito de afetividade ético-política, considerando-o fundamental para a transformação da sociedade, na medida em que atua sobre os sujeitos como uma força libertadora ou escravizadora, fomentando movimentos de inclusão-exclusão. Além do caráter mediacional na constituição do psiquismo (LANE, 2006), a afetividade é tomada como uma capacidade de o indivíduo transformar seus instintos na consciência, atribuindo-os significados, mediando as afecções a partir dos signos construídos socialmente, podendo aumentar e diminuir a sua potência de ação e as suas implicações psicossociais no encontro com os outros e as coisas (SAWAIA, 2011). 
À categoria afetividade relacionam-se as categorias simbolismo de espaço (POL; VALERA, 1999), apropriação do espaço (POL, 1996), identidade de lugar (PROSHANSKY, 1978), estima de lugar (BOMFIM, 2010), ajudando a compreender o modo como os lugares constituem os sujeitos com os quais se identificam e que os identifica, em um processo de afetação recíproca, e constroem modos de subjetivação. Há o destaque para a categoria social estima de lugar (BOMFIM, 2010), considerada basilar nos estudos do laboratório, com a qual se pode avaliar a apropriação, identificação e implicação do indivíduo com o lugar. Esta estima pode ser potencializadora, levando a ações de transformação e libertação; como pode ser despotencializadora, caracterizando uma vivência de padecimento, passividade e servidão.

\subsection{As temáticas das pesquisas e o compromisso social}

Com base na organização e categorização dos dados, foram encontradas 25 dissertações. Destas, 18 (72\%) foram desenvolvidas por mulheres, enquanto 07 (28\%) foram realizadas por homens. As pesquisas têm temáticas diversas, envolvendo a relação pessoaambiente e indivíduo-sociedade, bem como a articulação da Psicologia nas diversas Políticas Públicas, a exemplo de estudos voltados aos direitos de idosos, de adolescentes e jovens, de indígenas, de pessoas com deficiências visual e auditiva, e de pessoas em situação de rua. Temas relacionados ao direito à cidade e à moradia, à migração rural-urbana e à desapropriação do espaço. Há também pesquisas com enfoque nas Políticas de Saúde, voltadas para a formação e práxis do psicólogo nos diversos territórios de atuação, como centros de atenção psicossocial, centros e Residências de saúde da Família, no hospital, etc.

Dentre as temáticas destacadas, encontra-se a relação entre a estima de lugar, moradia e a participação social, articulada à ideia de intervenção no espaço urbano. Os estudos de Alencar (2010) e Lima (2010) buscaram demonstrar que os sentimentos de jovens em relação à comunidade onde residem repercute diretamente na participação destes em atividades comunitárias. Ou seja, quanto mais sentimentos de agradabilidade e segurança em suas comunidades, maior a potência para atuação e transformação destas, e vice-versa. Furlani (2007) e Ferreira (2006) observaram as influências dos ambientes (rural e urbano) sobre os projetos de vida de jovens, identificando as oportunidades de trabalho e de formação profissional como fatores de segurança e permanência no lugar onde moram ou de emigração na busca por melhores condições de vida. A participação comunitária foi tema do trabalho de Cabral (2015), que estudou a inter-relação entre o modo de vida comunitário, baseado em 
laços de solidariedade e cooperação, e a atuação dos moradores de uma comunidade praieira nos processos reivindicatórios de luta e participação política e social.

A relação com a cidade e o sofrimento urbano relacionado às formas de uso e de ocupação, foi tratado por Paz (2016) que se debruçou sobre o sofrimento e as vulnerabilidades inerentes ao enfrentamento cotidiano da exclusão e da desigualdade de pessoas em situação de rua. Neste sentido caminhou o estudo de Sousa (2017), no qual analisou a estima de jovens em relação à cidade de Fortaleza, apontando a articulação entre o modo de vida na cidade e o adoecimento psíquico, em especial ao fenômeno do suicídio. O ambiente citadino também foi objeto de Silva (2019), que buscou conhecê-lo a partir da afetividade de seus habitantes, investigando o papel da paisagem urbana, demonstrando como esta extrapola a sua materialidade e adentra em questões subjetivas, evocando afetividades.

Ribeiro (2015) examinou a existência de afetos (des)potencializadores que facilitam/dificultam os processos de apropriação e de identificação de moradores em relação ao bairro onde vivem. Por sua vez, Bertini (2006), pesquisou os afetos de idosos quanto ao centro da cidade de Fortaleza, demonstrando o impacto das transformações urbanas nos sentimentos de idosos, considerados testemunhas vivas do percurso cultural, histórico e urbanístico deste lugar. O público idoso também foi alvo das pesquisas de Ponte (2010) e Vieira (2012), os quais analisaram os afetos vinculados à relação idoso-abrigo/situação de abrigamento, abordando as condições de moradia (Lares de Longa Permanência) com o nível de satisfação dos idosos residentes, bem como os processos de apropriação do espaço e sua relação com o envelhecimento. Ainda em relação ao ambiente abrigo, Ribeiro (2008) investigou os afetos de adolescentes quanto à sua família de origem, destacando o papel da instituição como mediadora de afetos e de direitos, capaz de potencializar ou despotencializar para a conquista e a efetivação do direito à convivência familiar e comunitária.

A questão dos conflitos fundiários foi investigada por Pacheco (2018), que analisou as implicações psicossociais decorrentes das disputas de poder advindos do processo de desapropriação de uma comunidade, alertando que as intervenções urbanísticas e a especulação imobiliária acentuam o caráter segregacionista do desenvolvimento urbano, impactando a vida da parcela pobre da população que se torna o alvo de desapropriações e remoções. Nessa mesma direção, mas no contexto rural, Martins (2020) se debruçou sobre os processos de desapropriação compulsória pelas obras de um projeto público e as práticas de resistência desenvolvidas pela população. Já Bandeira (2012) analisou as congruências e incongruências entre as diretrizes urbanísticas de um plano de habitação e reabilitação elaborado pelo poder público e os afetos e as expectativas dos moradores deste espaço. 
A discussão entre afetividade e ambiência de trabalho nas políticas de saúde foi tema das pesquisas de Feitosa (2014) e Silva (2012), nas quais se discutiram os afetos quanto às políticas e espaços de atuação de psicólogos nas Residências Integradas de Saúde da Família e nas Equipes de Saúde da Família, respectivamente, e seus impactos na formação e na práxis profissional. Com olhar semelhante, Félix (2011) investigou a perspectiva dos trabalhadores dos Centros de Atenção Psicossocial. Os estudos evidenciaram uma estima de lugar despotencializadora associada às condições de gestão do serviço e de trabalho, à precariedade laboral, à ideologia que ampara a demanda pelo serviço e à prática profissional oferecida nesses locais. O ponto de vista do usuário foi abordado na análise de Barreto (2017) acerca da estima de lugar das pessoas atendidas pelo Centro de Saúde da Família, na qual defendeu que conhecer os afetos sobre o ambiente amplia as possibilidades de ações e serviços mais eficazes, uma maior implicação do usuário com um modo de viver saudável, bem como comunidades mais participativas, autônomas e empoderadas com o seu processo de saúde.

O ambiente hospitalar foi alvo das investigações de Pinheiro (2009), que analisou a influência desse ambiente nas manifestações e expressões de dor por pacientes oncológicos, e Lima (2013), que relacionou a morte aos sentimentos e às emoções das profissionais de psicologia na inter-relação com o ambiente do hospital enquanto local de trabalho.

Quanto às necessidades especiais, Martins (2015) discutiu a relação entre a estima de lugar e as condições de acessibilidade dos espaços, demonstrando o impacto das vivências urbanas de pessoas com deficiência visual como afetos (des)potencializadores de sua ação na cidade. Nesta mesma direção, orientou-se Augusto (2016), ao abordar as condições de acessibilidade de alunos surdos em relação ao ambiente acadêmico, questionando se as políticas de inclusão são suficientes para tornar a universidade acessível. A partir dos autores, o lugar e suas condições de usufruto e de acessibilidade são entendidos como uma dimensão importante na dialética exclusão-inclusão das pessoas com deficiência.

O ambiente esportivo foi pesquisado por Viana (2009), que estudou as emoções de atletas de competição de diversas modalidades. Por meio da articulação entre a Psicologia Ambiental e a Psicologia do Esporte, verificou-se que uma vinculação positiva com o ambiente é potencializadora das ações dos indivíduos, melhorando o desempenho, bem como sinalizando a necessidade que técnicos e psicólogos desportivos planejem o envolvimento dos atletas, atentando para questões socioemocionais no ambiente esportivo de competição.

Embora defendidas dentro do recorte temporal desta pesquisa, há uma dissertação (MELO, 2019) e duas teses (FEITOSA, 2019; PARENTE, 2020) ainda não indexadas no Repositório Institucional e, por isso, não estão integradas na análise final deste trabalho. No 
entanto, por encontrarem-se mencionadas no Lattes da coordenadora do LOCUS, e devido à importância dos estudos realizados, serão apresentados brevemente nesta seção. Em sua dissertação, Melo (2019) discute os aspectos epistemológicos e ontológicos da política de habitação do Programa Federal Minha Casa, Minha Vida, e as especificidades psicossociais sobre o lugar da mulher como beneficiária deste Programa. A pesquisa foi realizada em um conjunto habitacional em Sobral-Ceará, resultando na compreensão de que as mulheres se vinculavam às suas casas por necessidades de lugar próprio, significando a aquisição como "um sonho realizado".

Em relação às teses, a primeira defendida no LOCUS foi a de Feitosa (2019), que abordou os direitos dos povos indígena, compreendendo os afetos e os conflitos implicados nas vivências de lideranças indígenas ante as ameaças, principalmente, ao seu povo, à sua sobrevivência e à sua cultura. $\mathrm{O}$ estudo explicitou um movimento sócio-histórico dialético em que se expressam as concepções das lideranças sobre o ser indígena como implicação com a cultura, a ancestralidade e o compromisso com as futuras gerações, impulsionando a luta em defesa da Mãe Terra. Já os afetos despotencializadores relacionam-se aos conflitos internos e externos, à falta de reconhecimento e apoio e fragilização dos laços entre iguais e com os lugares. A tese de Parente (2020) se debruçou sobre o fenômeno dos afetos vivenciados em relação ao patrimônio cultural no contexto da cidade de Sobral-Ceará. No trabalho, o autor apresenta como a dinâmica transacional de moradores de áreas urbanas com o patrimônio cultural, material ou imaterial, traz implicações sociais e não só no desenvolvimento infraestrutural, mas nos usos político-econômicos e no campo dos afetos.

\subsection{Os procedimentos metodológicos: captando afetos e lugares}

Pesquisas "[...] são frutos de determinada inserção no real, nele encontrando suas raízes e seus objetivos" (MINAYO, 2001 p.18), devendo o método acompanhar a dinâmica do meio em que a pesquisa se insere para responder às práxis na vida cotidiana pautada na realidade (MONTERO, 2007). Ao analisar as produções do Locus, percebeu-se que as pesquisas seguiram a historicidade dos fenômenos, tendo seus métodos transformados conforme as demandas sociais se apresentavam.

Aproximadamente $52 \%$ dos trabalhos utilizaram somente essa perspectiva, a saber: Pinheiro (2009), Ponte (2010), Lima (2010), Félix (2011), Silva (2012), Vieira (2012), Lima (2013), Feitosa (2014), Martins (2015), Ribeiro (2015), Paz (2016), Augusto (2016) e Silva (2019). Os demais 48\%, além da perspectiva qualitativa, utilizaram suporte estatístico, 
característico das abordagens quantitativas: Bertini (2006), Ferreira (2006), Furlani (2007), Ribeiro (2008), Viana (2009), Alencar (2010), Bandeira (2012), Cabral (2015), Sousa (2017), Barreto (2017), Pacheco (2018) e Martins (2020). É importante salientar que todas as pesquisas com estatística se apresentaram com o caráter complementar à qualitativa, devendose, principalmente, à utilização de sua composição integral, apresenta uma escala psicométrica (BOMFIM et al., 2014).

Minayo (2001, p.15) afirma que "[...] o objeto das ciências sociais é essencialmente qualitativo", uma vez que as pesquisas buscam responder às questões particulares em um nível de realidade que, geralmente, não pode ser alcançado pela perspectiva quantitativa. No entanto, salienta que os métodos não são excludentes ou opostos, mas se complementam de modo a abranger a realidade e a romper dicotomias. Nos estudos, alguns autores salientaram a importância e potencialidade da natureza mista, principalmente no que diz respeito à Escala de Estima de Lugar e aos Mapas Afetivos (CABRAL, 2015; PACHECO, 2018; MARTINS, 2020).

Quanto aos procedimentos para a construção do corpus das pesquisas, como mostra o Quadro 02, o principal método utilizado é o Instrumento Gerador de Mapas Afetivos (IGMA), aparecendo em 22 pesquisas (88\%). Este método foi desenvolvido por Bomfim (2010), consistindo em um modo qualitativo e quantitativo de coleta e análise de dados, que utiliza como síntese interpretativa a comparação entre imagens e linguagens obtidas por meio de desenhos, metáforas e escores da Escala de Estima de Lugar (BOMFIM et al., 2014).

Como resultado, obtém-se a construção de mapas afetivos que expressam os sentimentos e as emoções e a implicação psicossocial do indivíduo em relação a um ambiente de sua realidade. O IGMA já foi utilizado com adolescentes, adultos, idosos, homens e mulheres. Há pesquisas com deficientes visuais e auditivos, pacientes oncológicos, etc., bem como aplicado em diversos contextos, como escolas, instituições de saúde, abrigos de longa permanência, comunidades e bairros (zonas rural e urbana). Observa-se que a utilização deste instrumento tem contribuído para o aperfeiçoamento do método ao longo dos anos, por ampliar os contextos de aplicação e a forma como ele é utilizado.

Nas pesquisas, destacam-se também a Entrevista (52\%), Diário de Campo (28\%), Grupo Focal/Círculo de Cultura (24\%) e Observação participante (20\%). Além destes, há Revisão Bibliográfica (8\%), Autobiografia/Narrativa Ambiental (8\%), Trilhas/Caminhadas (8\%), Questionários (8\%), Investigação-Ação-Participativa (4\%), Método DialógicoVivencial (4\%) e Documental/Prontuários (4\%). Vale salientar que os métodos, conforme apresenta o Quadro 01, não foram utilizados separadamente, $80 \%$ das pesquisas utilizaram 
dois métodos ou mais, caracterizando-se como multimétodos. Esta abordagem se define pelo uso de dois ou mais métodos, qualitativos e/ou quantitativos, tendo o "[...] propósito de diminuir os vieses inerentes à adoção de procedimentos que ressaltem apenas um aspecto do objeto em estudo" (GUNTHER; ELALI; PINHEIRO, 2011, p. 241-242). É interessante pontuar, ainda, que a referida abordagem coaduna com os pressupostos da Psicologia Ambiental, pelo caráter transdisciplinar da área e pela forma que estuda as interações pessoaambiente, em diálogo com outros campos do saber.

Quadro 01 - Combinação metodológica

\begin{tabular}{|c|c|c|}
\hline $\begin{array}{l}\text { Porcentagem } \\
(\%)\end{array}$ & Métodos & Pesquisas \\
\hline \multirow{2}{*}{$\begin{array}{l}\text { Um único } \\
\text { método } \\
20 \%\end{array}$} & $\begin{array}{l}\text { Instrumento Gerador de Mapas } \\
\text { Afetivos. }\end{array}$ & $\begin{array}{l}\text { Bertini (2006), Viana (2009), Félix } \\
\text { (2011), Sousa (2017). }\end{array}$ \\
\hline & Entrevista. & Ribeiro (2015). \\
\hline \multirow{9}{*}{$\begin{array}{l}\text { Multimétodos } \\
\mathbf{8 0 \%}\end{array}$} & $\begin{array}{l}\text { Instrumento Gerador de Mapas } \\
\text { Afetivos e Entrevista. }\end{array}$ & $\begin{array}{l}\text { Furlani (2007), Lima (2013), Feitosa } \\
\text { (2014) e Barreto (2017). }\end{array}$ \\
\hline & $\begin{array}{l}\text { Instrumento Gerador de Mapas } \\
\text { Afetivos, Entrevista, Observação, } \\
\text { Grupo Focal e Diário de Campo }\end{array}$ & $\begin{array}{l}\text { Vieira (2012), Cabral (2015), Pacheco } \\
\text { (2018) e Martins (2020). }\end{array}$ \\
\hline & $\begin{array}{l}\text { Instrumento Gerador de Mapas } \\
\text { Afetivos, Observação-Participante, } \\
\text { Diário de Campo e Entrevista }\end{array}$ & Ribeiro (2008) e Augusto (2016). \\
\hline & $\begin{array}{l}\text { Instrumento Gerador de Mapas } \\
\text { Afetivos e Questionário. }\end{array}$ & Bandeira (2012) e Martins (2015). \\
\hline & $\begin{array}{l}\text { Instrumento Gerador de Mapas } \\
\text { Afetivos, Trilhas e Grupo Focal. }\end{array}$ & Alencar (2010) \\
\hline & $\begin{array}{l}\text { Método Dialógico Vivencial, } \\
\text { Círculo de Cultura, Caminhada } \\
\text { Comunitária, Diário de Campo. }\end{array}$ & Lima (2010). \\
\hline & $\begin{array}{l}\text { Instrumento Gerador de Mapas } \\
\text { Afetivos e Grupo Focal. }\end{array}$ & Ferreira (2006) \\
\hline & Revisão Bibliográfica e Entrevista. & Silva (2012) \\
\hline & $\begin{array}{l}\text { Revisão Bibliográfica, Diário de } \\
\text { Campo, Instrumento Gerador de } \\
\text { Mapas Afetivos e Observação. }\end{array}$ & Paz (2016). \\
\hline
\end{tabular}




\begin{tabular}{|l|l|l|}
\hline & $\begin{array}{l}\text { Observação, Instrumento Gerador } \\
\text { de Mapas Afetivos, Prontuários e } \\
\text { Entrevista. }\end{array}$ & Pinheiro (2009) \\
\hline $\begin{array}{l}\text { Instrumento Gerador de Mapas } \\
\text { Afetivos e Autobiografia } \\
\text { Ambiental. Ponte (2010) }\end{array}$ \\
\hline $\begin{array}{l}\text { Instrumento Gerador de Mapas } \\
\text { Afetivos, Narrativa Ambiental e } \\
\text { Diário de Campo. Silva (2019). }\end{array}$ \\
\hline
\end{tabular}

Fonte: Elaborado pelos autores.

Dentre as combinações de métodos mais comuns, tem-se: 1) Instrumento Gerador de Mapas Afetivos e Entrevista; e 2) Instrumento Gerador de Mapas Afetivos, Entrevista, Observação, Grupo Focal e Diário de Campo. Nessas combinações, os pesquisadores apontaram a utilização das Entrevistas, Grupos Focais e Diário de Campo a fim de aprofundar as discussões sobre as temáticas e imagens afetivas advindas dos resultados do Instrumento Gerador de Mapas Afetivos.

Quanto aos procedimentos de análise, há grande destaque para a Análise de Conteúdo de Bardin (1977), que consiste em um conjunto de técnicas e/ou procedimentos sistemáticos de análise da comunicação. Por meio dela, o pesquisador obtém determinados indicadores com os quais pode fazer inferências de conhecimentos sobre conteúdos presentes, explícita e implicitamente, na produção e recepção da comunicação do fenômeno estudado. Mais ou menos 52\% utilizaram essa perspectiva como principal ferramenta de interpretação: Pinheiro (2009), Ponte (2010), Lima (2010), Félix (2011), Silva (2012), Vieira (2012), Lima (2013), Feitosa (2014), Martins (2015), Ribeiro (2015), Paz (2016), Augusto (2016) e Silva (2019). Outras 11 pesquisas (44\%), além dela, contaram com o suporte da estatística: Bertini (2006), Ferreira (2006), Furlani (2007), Ribeiro (2008), Viana (2009), Alencar (2010), Bandeira (2012), Cabral (2015), Sousa (2017), Pacheco (2018) e Martins (2020). Somente um estudo (Barreto, 2017) utilizou Análise de Discurso e Análise estatística complementar.

No geral, obteve-se que $96 \%$ dos estudos desenvolvidos no laboratório utilizam a Análise de Conteúdo para trabalhar com as informações. É importante destacar que um dos principais motivos pela escolha da Análise de Conteúdo diz respeito à coerência entre essa e o Instrumento Gerador de Mapas Afetivos, uma vez que o IGMA, em sua constituição, conta com os procedimentos de codificação e interpretação de dados da Análise de Conteúdo (Bomfim, 2010). É relevante, ainda, pontuar que algumas pesquisas utilizaram softwares de análises qualitativas e quantitativas. Para análises estatísticas, Ferreira (2006), Furlani (2007), 
Ribeiro (2008), Cabral (2015) utilizaram o Statistical Package for the Social Sciences (SPSS); e Sousa (2017) e Barreto (2017) utilizaram, respectivamente, o Microsoft Excel e o Mplus. Já para análise qualitativa, Feitosa (2014) contou com o auxílio do software Atlas.ti.

Quanto ao sexo dos participantes dos estudos, $92 \%$ das pesquisas foram desenvolvidas tanto com homens como também com mulheres. Apenas duas pesquisas foram desenvolvidas somente com um gênero, sendo a de Ponte (2010) com homens; e a de Lima (2013) com mulheres. Em relação à faixa etária, conforme o Quadro 05, 60\% das pesquisas foram desenvolvidas com adultos em geral, acima de 18 anos. Em seguida, aparecem as pesquisas desenvolvidas somente com jovens (20\%), entre os 18 a 29 anos; Idosos, acima de 60 anos (12\%); e adolescentes (12\%). Nenhuma pesquisa teve o enfoque sobre questões de raça, gênero ou orientação sexual.

Em relação aos lugares de realização das pesquisas, 76\% delas foram realizadas na capital, Fortaleza; seguido por $16 \%$ no interior (FERREIRA, 2006; CABRAL, 2015; BARRETO, 2017; MARTINS, 2020); e 08\% abrangendo interior e capital (FURLANI, 2007; FEITOSA, 2014). Ao integrar as informações sobre as temáticas das pesquisas, apresentadas anteriormente, com os procedimentos metodológicos adotados, é possível compreender mais amplamente, em consonância com os contextos psicossociais dos participantes, a importância da relação entre os fenômenos de estudo, os métodos utilizados e os alcances de cada pesquisa.

\section{CONSIDERAÇÕES FINAIS}

Em 2020, o LOCUS completou 17 anos. Quatorze anos já se passaram desde que a primeira dissertação produzida dentro do laboratório foi defendida no Programa de PósGraduação em Psicologia da Universidade Federal do Ceará. Ao longo desses anos, foram desenvolvidas 26 dissertações e 02 teses. Esse trabalho de análise das produções demarca a preservação da história do laboratório e reconhece suas contribuições científicas à psicologia, em especial, às Psicologias Ambiental e Social. Além de traçar um percurso histórico, temático e metodológico do laboratório, reflete também parte da história do PPGP-UFC, com suas consequentes contribuições científicas e sociais.

Os estudos desenvolvidos abrangem diversos contextos em vulnerabilidades sociais, da cidade ao campo, dos bairros nobres às periferias, das universidades às escolas, almejando analisar e intervir nos processos psicossociais que segregam e despotencializam as vivências humanas. Verificou-se o caráter interdisciplinar voltado para a compreensão dos fenômenos 
em suas totalidades, apreendendo as dinâmicas físicas, socioculturais, psicológicas e políticas. Embora a maioria das pesquisas utilize a mesma base teórica, a natureza qualitativa e o Instrumento Gerador de Mapas Afetivos, observou-se em cada uma o aprofundamento de categorias teóricas, o alcance de novos territórios de atuação, a adaptação dos métodos utilizados e uma nova leitura sobre os fenômenos.

As contribuições das produções do LOCUS no PPGP-UFC extrapolam o campo da teorização ao proporcionar reflexões sobre uma práxis profissional ético-politicamente engajada, que se concatena na famosa frase de Kurt Lewin: "nada mais prático do que uma boa teoria". Vê-se então, as pesquisas se tornarem práticas de transformação social, seja pelo desenvolvimento de ações de extensão ou pelas atuações profissionais daquela cuja formação foi atravessada pela vivência no laboratório.

\section{REFERÊNCIAS}

ALENCAR, H. F. Participação social e estima de lugar: caminhos traçados por jovens estudantes moradores de bairros da Regional III da Cidade de Fortaleza pelos mapas afetivos (Dissertação de Mestrado). Universidade Federal do Ceará, Fortaleza, 2010.

AUGUSTO, D. M. Afetividade e acessibilidade: um estudo com alunos surdos em ambiente universitário (Dissertação de Mestrado). Universidade Federal do Ceará, Fortaleza, 2016.

BANDEIRA, B. S. Estudo da afetividade de moradores do centro de Fortaleza-CE frente ao Plano Habitacional para Reabilitação da Área Central de Fortaleza-CE (Dissertação de Mestrado). Universidade Federal do Ceará, Fortaleza, 2012.

BARDIN, L. Análise de Conteúdo. Lisboa: Edições 70, 1977.

BARROS, J. P. P.; ANTUNES, D. C.; MELLO, R. P. Políticas públicas, violências e modos de subjetivação: o programa de pós-graduação em psicologia da UFC e a problematização de processos de vulnerabilização social. In: BARROS, J. P. P.; ANTUNES, D. C.; MELLO, R. P. (Orgs.). Políticas de vulnerabilização social e seus efeitos: estudos do programa de pósgraduação em psicologia da Universidade Federal do Ceará (UFC). Fortaleza: Imprensa Universitária, 2020.

BARROS, J. P. P. et al. Problemáticas sociais e suas relações com a pesquisa e a extensão: contribuições do Programa de Pós-Graduação em Psicologia da UFC. Estudos de Psicologia (Natal), v. 24, n.2, p.147-158, 2019. https://dx.doi.org/10.22491/1678-4669.20190017

BARRETO, E. H. F. L. Estima de lugar e implicações com a saúde: a perspectiva dos usuários de um Centro de Saúde do Nordeste do Brasil (Dissertação de Mestrado). Universidade Federal do Ceará, Fortaleza, 2017. 
BERTINI, F. M. A. Centro da cidade de Fortaleza, lugar das transformações: o idoso e os afetos implicados (Dissertação de Mestrado). Universidade Federal do Ceará, Fortaleza, 2006.

BOMFIM, Z. A. C. Cidade e Afetividade: Estima e Construção de Mapas Afetivos de Barcelona e São Paulo. Fortaleza, Edições UFC, 2010.

BOMFIM, Z. A. C. et al. Affective maps: validating a dialogue between qualitative and quantitative methods. In: GARCIA-MIRA, R; DUMITRU, A. (Eds.). Urban Sustainability: Innovative spaces, vulnerabilities and opportunities. A Coruña, ESP: Deputación da Coruña \& Instituto de Investigación Xoan Vicente Viqueira, 2014.

CABRAL, D. W. A. Relação afetiva pessoa-ambiente na Prainha do Canto Verde: processos de participação comunitária (Dissertação de Mestrado). Universidade Federal do Ceará, Fortaleza, 2015.

COSTA, A. B.; ZOLTOWSKI, A. P. C. Como escrever um artigo de revisão sistemática. In: KOLLER, S. H.; COUTO, M. C.P.; HOHENDORFF, J. V. Manual de produção científica. Porto Alegre: Penso Editora, 2014.

ELALI, G. A.; PELUSO, M. L. Interdisciplinaridade. In: CAVALCANTE, S; ELALI, G. (Org.). Temas básicos em psicologia ambiental. Petrópolis (RJ): Editora Vozes, 2011.

FEITOSA, M. Z. S. Afetividade na residência integrada em saúde: o psicólogo no território de form"ação" (Dissertação de Mestrado). Universidade Federal do Ceará, Fortaleza, 2014.

FÉLIX, F. M. F. Afetividade e trabalho: uma leitura dos CAPS gerais de Fortaleza mediada pelos mapas afetivos (Dissertação de Mestrado). Universidade Federal do Ceará, Fortaleza, 2011.

FERREIRA, K. P. M. Ficar ou partir? afetividade e migração de jovens do sertão semiárido cearense (Dissertação de Mestrado). Universidade Federal do Ceará, Fortaleza, 2006.

FURLANI, D. D. Juventude e afetividade: tecendo projetos de vida (Dissertação de Mestrado). Universidade Federal do Ceará, Fortaleza, 2007.

GARCIA-MIRA, R. La Ciudad Percibida: Una Psicología ambiental de los Barrios de A Coruña. Universidad da Coruña, 1997.

GUNTHER, H., ElAlI, G. A.; PINHEIRO, J. Q. Multimétodos. In: CAVALCANTE, S; ELALI, G. (Org.). Temas básicos em psicologia ambiental. Petrópolis (RJ): Editora Vozes, 2011.

LANE, T. M. S. A Psicologia Social e uma nova concepção do homem para a Psicologia. In: LANE, T. M. S.; CODO, W. (Org.). Psicologia Social: o Homem Em Movimento. $8^{\mathrm{a}}$ ed. São Paulo, SP: Editora Brasiliense, 1989.

LANE, T. M. S. A mediação emocional na constituição do psiquismo humano. In: LANE, S. M. T; SAWAIA, B. B. Novas veredas da Psicologia Social. São Paulo: Brasiliense, 2006. 
LIMA, F. H. G. O psicólogo no ambiente do hospital e a afetividade: uma construção de sentidos sobre a morte (Dissertação de Mestrado). Universidade Federal do Ceará, Fortaleza, 2013.

LIMA, D. M. A. ProJovem Urbano da Escola Papa João XXIII do Bairro Vila União: significados atribuídos pelos jovens na perspectiva da psicologia comunitária e da psicologia ambiental (Dissertação de Mestrado). Universidade Federal do Ceará, Fortaleza, 2010.

LIMA, A. F.; GERMANO, I. M. P.; SABÓIA, I. B.; FREIRE, J. C. (2018). Si mesmo, outro e sociedade: reflexões sobre sujeito e cultura na contemporaneidade. In: LIMA, A. F.; GERMANO, I. M. P.; SABÓIA, I. B.; FREIRE, J. C. (Org.). Sujeito e subjetividades contemporâneas: estudos do programa de pós-graduação em psicologia da UFC. Fortaleza: Edições UFC, 2018.

MARTÍN-BARÓ, I. Desafios e perspectivas da Psicologia Latino-Americana. In: GUZZO, R. S. L.; LACERDA JUNIOR, F.. Psicologia Social para América Latina: o resgate da Psicologia da Libertação. Campinas, Sp: Alínea, 2011.

MARTINS, A. K. S. Mapas afetivos táteis: vivências urbanas não visuais na cidade de Fortaleza (Dissertação de Mestrado). Universidade Federal do Ceará, Fortaleza, 2015.

MARTINS, C. M. S. S. Afetividade em contextos de desapropriação: impactos psicossociais das obras do cinturão das águas do Ceará em comunidades rurais do município do Crato-CE (Dissertação de Mestrado). Universidade Federal do Ceará, Fortaleza, 2020.

MELO, B. B. A Casa: os sentidos de habitar para mulheres moradoras do conjunto habitacional Nova Caiçara/Sobral-Ceará (Dissertação de Mestrado não publicada). Universidade Federal do Ceará, Fortaleza, 2019.

MINAYO, M. C. S. Pesquisa Social: Teoria, método e criatividade. Petrópolis: Vozes, 2001.

MONTERO, M. Hacer para transformar: el método en la psicología comunitaria. Buenos Aires: Paidós, 2007.

MOSER, G. Psicologia Ambiental. Estudos de Psicologia (Natal), v.3, n.1, p.121-130, 1998.

PAZ, A. F. C. Liberdade ou sofrimento urbano? um estudo da estima de lugar de pessoas em situação de rua (Dissertação de Mestrado). Universidade Federal do Ceará, Fortaleza, 2016.

PACHECO, F. P. Afetividade e implicações psicossociais vividas por moradores de uma comunidade ameaçada de desapropriação (Dissertação de Mestrado). Universidade Federal do Ceará, Fortaleza, 2018.

PARENTE, J. R. F. Patrimônio Afetivo e Cultural no sítio histórico de Sobral-CE (Tese de doutorado não publicada). Universidade Federal do Ceará, Fortaleza, 2020.

PINHEIRO, G. R. (2009). Afetividade e ambiente hospitalar: construção de significados pelo paciente oncológico com dor (Dissertação de Mestrado). Universidade Federal do Ceará, Fortaleza, 2009. 
POL, E. La apropiación del espacio. In: IÑIGUEZ, L.; POL, E. (Org.). Cognición, representación y apropiación del espacio. Barcelona: Publicacions Universitat de Barcelona, 1996.

POL, E.; VALERA, S. Symbolisme de l'espace public et identitée sociale. Villes em Paralèlle, v. 28, n.29, 13-33, 1999.

PONTE, A. Q. Afetividade de idosos de vida religiosa consagrada e a moradia na casa de saúde: projetos de vida e processo de estabilização residencial (Dissertação de Mestrado). Universidade Federal do Ceará, Fortaleza, 2010.

PROSHANSKY, H. The City and the self-idenity. Enviroment and Behavior, v. 1, n.2, p.147-169, 1978.

RIBEIRO, L. L. Afetos em construção: narrativas e processos de apropriação do espaço pelos moradores da Cidade 2000 (Dissertação de Mestrado). Universidade Federal do Ceará, Fortaleza, 2015.

RIBEIRO, J. M. L. Laços afetivos que (des)ligam famílias, adolescentes e abrigo (Dissertação de Mestrado). Universidade Federal do Ceará, Fortaleza, 2008.

SAWAIA, B. B. O sofrimento ético-político como categoria de análise da dialética exclusão/inclusão. In: Sawaia, B. B. (Org.). As artimanhas da exclusão: uma análise éticopsicossocial da desigualdade. Petrópolis, RJ: Vozes, 2011.

SILVA, S. H. G. O direito à paisagem urbana: imagem e afetividade na construção de uma geografia do olhar (Dissertação de Mestrado). Universidade Federal do Ceará, Fortaleza, 2019.

SILVA, E. C. S. A psicologia e as políticas públicas de saúde: um estudo sobre a atuação da(o) psicóloga(o) na atenção primária à saúde no município de Fortaleza (Dissertação de Mestrado). Universidade Federal do Ceará, Fortaleza, 2012.

SOUSA, L. C. A. Juventude, suicídio e vida urbana: tecendo relações a partir da estima de lugar (Dissertação de Mestrado). Universidade Federal do Ceará, Fortaleza, 2018.

VIANA, L. G. Afetividade e ambiente esportivo: sentimentos e emoções de atletas de competição (Dissertação de Mestrado). Universidade Federal do Ceará, Fortaleza, 2009.

VIEIRA, A. C. C. Lar doce lar? Um estudo sobre afetividade de idosos residentes em instituições de longa permanência em Fortaleza (Dissertação de Mestrado). Universidade Federal do Ceará, Fortaleza (CE), 2012.

VYGOTSKY, L. S. (1996). Teoria e método em psicologia. São Paulo: Martins Fontes, 1996. 


\section{Como Referenciar este Artigo, conforme ABNT:}

PACHECO, F. P; SOUSA, L. E. E. M; BONFIM, Z. A. C. Revisão Sistemática das Produções do Laboratório de Pesquisa em Psicologia Ambiental. Rev. FSA, Teresina, v.18, n. 03, art. 12, p. 260278, mar. 2021.

\begin{tabular}{|l|c|c|c|}
\hline \multicolumn{1}{|c|}{ Contribuição dos Autores } & $\begin{array}{c}\text { F. P. } \\
\text { Pacheco }\end{array}$ & $\begin{array}{c}\text { L. E. E. M. } \\
\text { Sousa }\end{array}$ & $\begin{array}{c}\text { Z. A. C. } \\
\text { Bonfim }\end{array}$ \\
\hline 1) concepção e planejamento. & $\mathrm{X}$ & & \\
\hline 2) análise e interpretação dos dados. & $\mathrm{X}$ & $\mathrm{X}$ & \\
\hline 3) elaboração do rascunho ou na revisão crítica do conteúdo. & $\mathrm{X}$ & $\mathrm{X}$ & $\mathrm{X}$ \\
\hline 4) participação na aprovação da versão final do manuscrito. & $\mathrm{X}$ & $\mathrm{X}$ & $\mathrm{X}$ \\
\hline
\end{tabular}

